\title{
MORPHOMETRY OF THE SUBAXIAL CERVICAL SPINE PEDICLES IN THE ANATOLIAN POPULATION
}

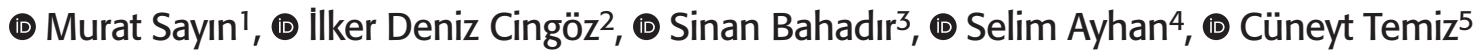 \\ 1 Izmir Private Health Hospital, Clinic of Neurosurgery, Izmir, Turkey \\ 2 Izmir Alsancak Nevvar Salih İsgören State Hospital, Clinic of Neurosurgery, İzmir, Turkey \\ ${ }^{3}$ Amasya University Faculty of Medicine, Department of Neurosurgery, Amasya, Turkey \\ ${ }^{4}$ Başkent University Hospital, Clinic of Neurosurgery, Ankara, Turkey \\ ${ }^{5}$ Manisa Celal Bayar University Faculty of Medicine, Department of Neurosurgery, Manisa, Turkey
}

\begin{abstract}
Objective: Transpedicular screw fixation for the subaxial cervical spine is considered to be more stable than other posterior fixation techniques despite its technical challenges. Thorough understanding of cervical pedicle anatomy and morphometric parameters is essential to avoid neurovascular injury during screw placement.

To evaluate subaxial cervical spine pedicle dimensions, screw starting points, and screw trajectories to provide data that might be representative of the entire Anatolian peninsula.

Materials and Methods: This retrospective study included 200 patients (2000 cervical pedicles). The distance from the junction of the lamina and spinous process to the entry point (DEP), pedicle width (PW), pedicle maximum axis length (PAL), pedicle transverse angle (PTA) in the axial plane, and pedicle height $(\mathrm{PH})$ in the sagittal plane were measured from $\mathrm{C} 3$ to $\mathrm{C} 7$ on computed tomography (CT) by two blinded observers.

Results: The mean values for DEP, PW, PAL, PTA and PHA ranged between $22.92 \mathrm{~mm}-23.75 \mathrm{~mm}, 4.99 \mathrm{~mm}-6.26 \mathrm{~mm}, 28.24 \mathrm{~mm}-36.01 \mathrm{~mm}, 33.52^{\circ}$ $34.60^{\circ}$ and $6.36 \mathrm{~mm}-7.03 \mathrm{~mm}$, respectively. The PW significantly increased in the rostrocaudal direction. The PAL was significantly different between the right and left sides at C3 in male patients. The PTA was significantly different between the right and left sides at C3 in female patients. The PH was greater than the PW at all levels on both sides.

Conclusion: Although surgical planning should be carried out on a case-by-case basis, the findings of the present study might be helpful for Turkish spine surgeons in decision-making for the accurate placement of cervical pedicle screws.

Keywords: Anatomy, computed tomography, morphometric analysis, pedicle, pedicle screw, subaxial cervical spine
\end{abstract}

\section{INTRODUCTION}

Numerous cervical spinal disorders, such as infections, tumours, traumatic injuries, and degenerative diseases, may result in instability and require cervical spinal instrumentation. The armamentarium for posterior cervical spine fixation includes interspinous wiring, laminar hooks, and screw fixation with rods and/or plates ${ }^{(1)}$. For the past two decades, lateral mass screw fixation has been the most preferred technique among spine surgeons as this technique is associated with lower complication risks and higher fusion rates ${ }^{(2)}$. Transpedicular screw fixation for the subaxial cervical spine, initially reported by Abumi et al.(3) and Jeanneret et al.(4) in 1994, is considered to be more stable than other posterior fixation techniques. However, the approach is technically demanding. The diameter of the pedicle is narrow, and there is a potential risk for serious neurovascular complications, including injuries to the vertebral artery, nerve root, and spinal cord ${ }^{(3,5)}$. Recently, spine surgeons are reporting a lower incidence rate of complications than initially considered, and are attempting to perform transpedicular screw fixation more frequently(b). Thorough understanding of cervical pedicle anatomy and morphometric parameters is essential to avoid neurovascular injury during screw placement.

Subaxial cervical spine morphometric values vary among different populations in the literature $\mathrm{e}^{(5,7-15)}$. To our knowledge, four morphometric studies with small sample sizes from Turkey have been reported in the English literature ${ }^{(7-9,11)}$. As various ethnic groups are present and immigration to big cities and interethnic marriage are common, Anatolia has a highly 
heterogeneous population. Thus, data obtained from a small group may not represent the entire Anatolian peninsula. The present study aimed to evaluate subaxial cervical spine pedicle dimensions, screw starting points, and screw trajectories, using computed tomography (CT), for providing data that might be representative of the entire Anatolian peninsula.

\section{MATERIALS AND METHODS}

This retrospective research, designed to investigate morphological properties of subaxial cervical spine in Anatolian population, included 200 consecutive patients (100 male and 100 female; 2000 cervical pedicles) who underwent standard CT for various reasons at a tertiary academic care unit between 2015 and 2017. The CT scans were obtained from radiology archive of the institution, and no clinical data of patients were retrieved. The informed consent for academic research had been taken. The inclusion criteria were fine quality images of subaxial cervical spine and age $>18$ years at the time of imaging. The exclusion criteria were evidence of any pathology related to a severely degenerative, congenital, traumatic, infectious, metabolic, or neoplastic spinal disease and prior cervical spine surgery since these conditions may have caused structural changes. The study population included patients who have origins in central, eastern and western Anatolian peninsula. All cervical spine CT scans were performed using the Somatom Sensation 16 (Siemens Medical Solutions, Erlangen, Germany) tomography system. Axial images were taken in $2 \mathrm{~mm}$ slice thickness, and then sagittal reconstructions with $2 \mathrm{~mm}$ thickness were obtained. The distance from the junction of the lamina and spinous process to the entry point (DEP), pedicle width $(\mathrm{PW})$, pedicle maximum axis length $(\mathrm{PAL})$, pedicle transverse angle (PTA) in the axial plane, and pedicle height $(\mathrm{PH})$ in the sagittal plane were measured for morphometric analysis of the subaxial cervical pedicles as was described in the literature ${ }^{(13)}$ (Table 1) (Figure 1). All measurements were performed by two blinded observers on one occasion.

\section{Statistical Analysis}

The mean and standard deviation values of the parameters were calculated at each level without considering sex initially and then considering sex (male and female patients separately). Normal distributions of numerical variables were calculated using the Shapiro-Wilk normality test and Q-Q graphics. Differences in measurements between the right and left pedicles were evaluated using the paired t-test, and comparisons of the measurements at different cervical vertebra levels were performed using the one-way repeated-measures analysis of variance. The Bonferroni test was used as a Posthoc test. An independent samples t-test was used to determine sex differences with regard to IPD. All statistical analyses were performed using IBM SPSS Statistics software, version 22.0 (IBM Corp., Armonk, NY, USA). A p-value <0.05 was considered statistically significant.

\section{RESULTS}

The study involved 200 Anatolian patients (100 of each sex) aged 18-78 years (mean 52 years). The mean age of the male patients was $47 \pm 20$ years, and the mean age of the female patients was $56 \pm 18$ years. Although the difference in age was statistically significant $(p<0.05)$, no correction was performed as age is not considered to be related to the measured parameters. The mean values of measured subaxial cervical pedicle
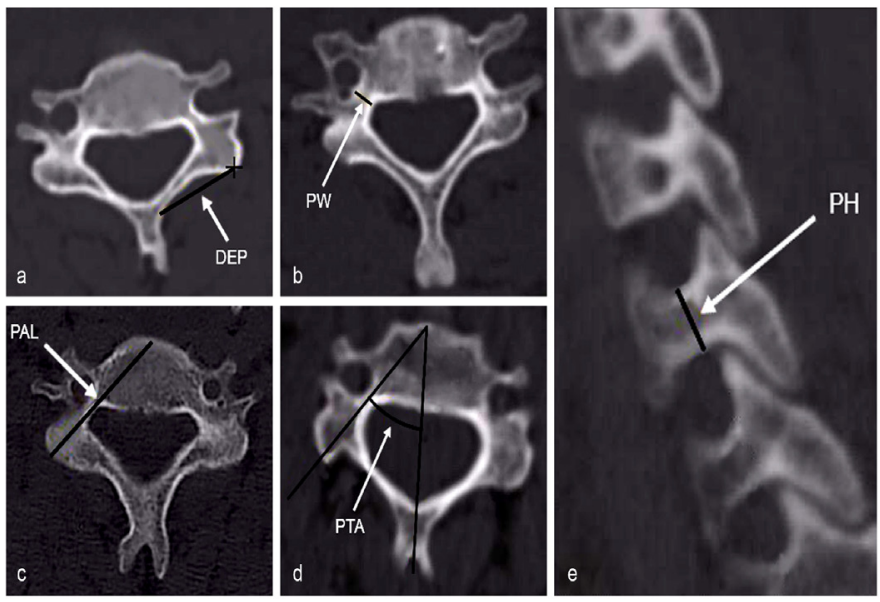

Figure 1. Parameters measured on computed tomography. Distance from the junction of the lamina and spinous process to the entry point (DEP) (a). Pedicle width (PW) (b). Pedicle axis length (PAL) (c). Pedicle transverse angle (PTA) (d). Pedicle height (PH) (e)

Table 1. Parameters measured on computed tomography

\begin{tabular}{|c|c|c|}
\hline Measurement & Abbreviation & Description \\
\hline $\begin{array}{l}\text { Distance from the junction of the lamina and } \\
\text { spinous process to the entry point }\end{array}$ & DEP & $\begin{array}{l}\text { Distance between the junction of the lamina and spinous process } \\
\text { and the pedicle screw entry point }\end{array}$ \\
\hline Pedicle width & PW & Mediolateral diameter of the pedicle at its narrowest part \\
\hline Pedicle axis length & PAL & $\begin{array}{l}\text { Distance between the posterior cortex of the lateral mass to the } \\
\text { anterior wall of the vertebral body along the pedicle axis }\end{array}$ \\
\hline Pedicle transverse angle & PTA & $\begin{array}{l}\text { Angle between the transverse pedicle axis and median sagittal } \\
\text { axis of the vertebra }\end{array}$ \\
\hline Pedicle height & $\mathrm{PH}$ & Rostrocaudal diameter of the pedicle at its narrowest part \\
\hline
\end{tabular}


morphological parameters are summarized in Table 2 and Table 3. The overall mean DEP ranged from $22.92 \mathrm{~mm}$ to 23.75 $\mathrm{mm}$, and the minimum DEP was $19.94 \mathrm{~mm}$. There were no significant differences between the right and left sides, except for C6. No statistical significance associated with gender was found for DEP. Post-hoc analysis revealed that the DEP was not significantly different between $\mathrm{C} 3$ and $\mathrm{C} 5, \mathrm{C} 4$ and $\mathrm{C} 5$, and $\mathrm{C} 6$, and $\mathrm{C} 7$ on the right side; and the DEP was significantly lower at $\mathrm{C} 7$ than at the other levels on the left side.

The overall mean PW ranged from $4.99 \mathrm{~mm}$ to $6.26 \mathrm{~mm}$, and the minimum PW was $4.11 \mathrm{~mm}$ at C6. There was no significant difference between the right and left side, except for $\mathrm{C} 3$ in the whole study group and for $\mathrm{C} 4$ in male patients. When comparing male and female patients, the PW was found to be larger at $\mathrm{C} 3$ and $\mathrm{C} 4$ but smaller at $\mathrm{C} 5, \mathrm{C} 6$, and $\mathrm{C} 7$ in male patients; however, the differences were found to be significant at $\mathrm{C} 3, \mathrm{C} 4$, and $\mathrm{C} 6$ on the right and at $\mathrm{C} 3$ and $\mathrm{C} 6$ on the left side. Post-hoc analysis revealed that the PW significantly increased in the rostrocaudal direction, except between $\mathrm{C} 4$ and $\mathrm{C} 5$, on both sides.

The overall mean PAL ranged from $28.24 \mathrm{~mm}$ to $36.01 \mathrm{~mm}$ There were no significant differences between the right and left sides for all vertebrae, except $\mathrm{C} 3$ in male patients. No significant differences were noted with regard to sex. Post-hoc analysis revealed that the PAL significantly increased from C3 to C7.

Table 2. The evaluated morphological parameters of pedicles in subaxial cervical spine

\begin{tabular}{|c|c|c|c|c|c|c|}
\hline & & DEP $(\mathrm{mm})$ & PW (mm) & PAL (mm) & PTA $\left({ }^{\circ}\right)$ & $\mathrm{PH}(\mathrm{mm})$ \\
\hline \multicolumn{7}{|c|}{ (Mean \pm standard deviation) } \\
\hline \multirow{3}{*}{ C3 } & Overall & $23.70 \pm 1.39$ & $5.00 \pm 0.15$ & $28.28 \pm 1.13$ & $33.90 \pm 1.33$ & $7.02 \pm 0.21$ \\
\hline & Right & $23.75 \pm 1.40$ & $4.99 \pm 0.16$ & $28.24 \pm 1.14$ & $33.96 \pm 1.36$ & $7.01 \pm 0.24$ \\
\hline & Left & $23.65 \pm 1.38$ & $5.02 \pm 0.15$ & $28.33 \pm 1.12$ & $33.84 \pm 1.31$ & $7.03 \pm 0.17$ \\
\hline \multirow{3}{*}{ C4 } & Overall & $23.52 \pm 1.40$ & $5.37 \pm 0.26$ & $30.44 \pm 1.54$ & $33.53 \pm 1.35$ & $6.88 \pm 0.40$ \\
\hline & Right & $23.48 \pm 1.43$ & $5.36 \pm 0.24$ & $30.42 \pm 1.55$ & $33.52 \pm 1.34$ & $6.87 \pm 0.41$ \\
\hline & Left & $23.55 \pm 1.36$ & $5.38 \pm 0.29$ & $30.46 \pm 1.53$ & $33.53 \pm 1.36$ & $6.90 \pm 0.40$ \\
\hline \multirow{3}{*}{ C5 } & Overall & $23.47 \pm 1.46$ & $5.31 \pm 0.58$ & $32.11 \pm 0.62$ & $33.71 \pm 1.39$ & $6.68 \pm 0.45$ \\
\hline & Right & $23.41 \pm 1.46$ & $5.26 \pm 0.58$ & $32.11 \pm 0.61$ & $33.73 \pm 1.40$ & $6.71 \pm 0.46$ \\
\hline & Left & $23.53 \pm 1.45$ & $5.36 \pm 0.58$ & $32.11 \pm 0.63$ & $33.69 \pm 1.38$ & $6.66 \pm 0.44$ \\
\hline \multirow{3}{*}{ C6 } & Overall & $23.29 \pm 1.53$ & $5.62 \pm 0.80$ & $34.30 \pm 0.94$ & $34.59 \pm 1.90$ & $6.43 \pm 0.63$ \\
\hline & Right & $22.94 \pm 1.57$ & $5.65 \pm 0.81$ & $34.33 \pm 1.00$ & $34.57 \pm 1.92$ & $6.36 \pm 0.67$ \\
\hline & Left & $23.65 \pm 1.42$ & $5.60 \pm 0.80$ & $32.26 \pm 0.89$ & $34.60 \pm 1.88$ & $6.49 \pm 0.58$ \\
\hline \multirow{3}{*}{$\mathrm{C7}$} & Overall & $22.96 \pm 1.62$ & $6.23 \pm 0.86$ & $36.00 \pm 0.93$ & $34.02 \pm 2.46$ & $6.65 \pm 0.61$ \\
\hline & Right & $22.92 \pm 1.63$ & $6.20 \pm 0.86$ & $35.99 \pm 0.94$ & $33.96 \pm 2.44$ & $6.65 \pm 0.60$ \\
\hline & Left & $23.00 \pm 1.62$ & $6.26 \pm 0.80$ & $36.01 \pm 0.93$ & $34.08 \pm 2.49$ & $6.65 \pm 0.61$ \\
\hline
\end{tabular}

DEP: Distance from the junction of the lamina and spinous process to the entry point, PW: Pedicle width, PAL: Pedicle maximum axis length, PTA: Pedicle transverse angle, PH: Pedicle height

Table 3. The summary of evaluated morphological parameters based on genders

\begin{tabular}{lllllll}
\hline & \multicolumn{7}{c}{ DEP $(\mathrm{mm})$} & PW $(\mathrm{mm})$ & PAL $(\mathrm{mm})$ & PTA $\left({ }^{\circ}\right)$ & PH $(\mathrm{mm})$ \\
\hline \multirow{2}{*}{ C3 } & Male & $23.77 \pm 1.38$ & $5.08 \pm 0.14$ & $28.29 \pm 1.13$ & $33.83 \pm 1.39$ & $7.03 \pm 0.21$ \\
\cline { 2 - 7 } & Female & $23.63 \pm 1.40$ & $4.92 \pm 1.12$ & $28.28 \pm 1.13$ & $33.97 \pm 1.27$ & $7.01 \pm 0.20$ \\
\hline \multirow{2}{*}{ C4 } & Male & $23.55 \pm 1.41$ & $5.44 \pm 0.26$ & $30.46 \pm 1.55$ & $33.45 \pm 1.37$ & $6.89 \pm 0.37$ \\
\cline { 2 - 7 } & Female & $23.49 \pm 1.38$ & $5.29 \pm 0.25$ & $30.42 \pm 1.54$ & $33.60 \pm 1.33$ & $6.88 \pm 0.43$ \\
\hline \multirow{2}{*}{ C5 } & Male & $23.55 \pm 1.45$ & $5.30 \pm 0.50$ & $32.08 \pm 0.59$ & $33.76 \pm 1.39$ & $6.68 \pm 0.44$ \\
\hline \multirow{2}{*}{ C6 } & Female & $23.39 \pm 1.45$ & $5.32 \pm 0.65$ & $32.14 \pm 0.64$ & $33.66 \pm 1.40$ & $6.69 \pm 0.46$ \\
\hline \multirow{2}{*}{ C7 } & Male & $22.27 \pm 1.57$ & $5.48 \pm 0.70$ & $34.36 \pm 0.94$ & $34.54 \pm 1.84$ & $6.43 \pm 0.65$ \\
\hline & Female & $23.32 \pm 1.51$ & $5.77 \pm 0.87$ & $32.23 \pm 0.94$ & $34.63 \pm 1.96$ & $6.43 \pm 0.61$ \\
\hline & Male & $23.02 \pm 1.60$ & $6.19 \pm 0.89$ & $36.04 \pm 0.96$ & $34.02 \pm 2.50$ & $6.60 \pm 0.59$ \\
\hline
\end{tabular}

DEP: Distance from the junction of the lamina and spinous process to the entry point, PW: Pedicle width; PAL: Pedicle maximum axis length, PTA: Pedicle transverse angle, $\mathrm{PH}$ : Pedicle height 
The overall mean PTA ranged from $33.52^{\circ}$ to $34.60^{\circ}$. There were no significant differences between the right and left sides for all vertebrae, except for C3 in female patients. Significant gender-specific differences were found at $\mathrm{C} 3$ on the right and C5 on the left. Post-hoc analysis revealed significant differences in the PTA between C 6 and other vertebrae above. There were no significant differences with regard to C7. The values for C5 and other vertebrae above were similar.

The overall mean $\mathrm{PH}$ ranged from $6.36 \mathrm{~mm}$ to $7.03 \mathrm{~mm}$. The $\mathrm{PH}$ was greater than the PW at all levels on both sides. There were no significant differences between the right and left sides for all vertebrae, except C6 in male patients. Gender was not found to have a significant effect on $\mathrm{PH}$. Post-hoc analysis revealed that the $\mathrm{PH}$ significantly decreased from $\mathrm{C} 3$ to $\mathrm{C} 6$ and then increased slightly from C6 to C7, but this change was not statistically significant.

\section{DISCUSSION}

Among the spinal segments, the cervical spine has the greatest range of motion, and this makes it more susceptible to degenerative or traumatic pathologies. Other issues, such as infections, tumours, and metabolic diseases, may also affect the cervical spine and may reduce stability; thus, cervical instrumentation with or without fusion may be unavoidable in the setting of instability under such circumstances. The most commonly used posterior instrumentation technique in current practice is lateral mass fixation ${ }^{(2)}$. For the subaxial cervical spine, Abumi et al.(3) and Jeanneret et al.(4) described transpedicular screw fixation in 1994. Several biomechanical studies have demonstrated that cervical pedicle screw fixation is more stable than other posterior fixation methods, but its use is limited owing to the risk of serious injury to adjacent neurovascular structures ${ }^{(16)}$.

Unlike the thoracic and lumbar vertebrae, the cervical vertebrae, with the exception of $\mathrm{C} 7$, have transverse foramina on the transverse process, allowing passage of the vertebral artery and vertebral veins. Owing to their small size and unique anatomical features, the most severe complications associated with transpedicular screw fixation are injuries to the vertebral arteries, spinal cord, and nerve roots. To avoid complications, detailed knowledge of pedicle anatomy, including the pedicle width, $\mathrm{PH}$, and anteroposterior trajectory, is required during transpedicular screw fixation.

Several cadaveric and radiological studies on cervical spine morphology have been conducted ${ }^{(6,10,17)}$. Although some similarities were noted, there were differences that may be attributed to the different study populations. Even ethnic problems can be seen now in any city, and one should not exclude this variable totally, Turkey includes several ethnic populations. Thus, it is difficult to generalize the findings of previous publications on the Turkish population with small sample sizes ${ }^{(7-9,11)}$. We have performed this study on a larger group of individuals who have origins from the central to eastern and western Anatolian peninsula.

\section{Right vs. Left and Male vs. Female}

There is a limited amount of studies analysing the right and left sides in the literature. The pedicle-spinous process distance, PW, and PAL were shown to be statistically significant ${ }^{(8,14)}$. In our study, every parameter showed differences between the right and left sides at least in one spinal segment, and the calculated amount of differences were highest at C3, followed by $\mathrm{C6}$. Although there was no general pattern, the differences in results can be attributed to the following: 1) a larger sample size in this study than in previous studies, which may have resulted in small differences becoming apparent, 2) differences in demographics of the study population, and 3) differences in inter-rater reliability.

There have been reasonably consistent reports on differences according to gender. Although some researchers found out differences between sexes in the measurement of $\mathrm{PW}, \mathrm{PH}$, and PAL, there were also others reporting no differences ${ }^{(7,13,14)}$. To our knowledge, only Uğur et al.'s(7) study demonstrated a statistically significant difference in the PTA between male and female patients $^{(7)}$. We found differences in the PW and DEP according to sex. However, contradictory to previous findings, there were no significant differences in the $\mathrm{PH}$ and PAL according to sex. Moreover, there were significant differences in the PTA at some levels between male and female patients, as reported by Uğur et al. $^{(7)}$. We do not believe that the absence of significance for the $\mathrm{PH}$ and PAL can be attributed to sample size, as the sample size was large enough to demonstrate differences. However, it might be associated with population characteristics, as the inter-rater reliability for the PAL has been shown to be intermediate to good and that for the $\mathrm{PH}$ has been shown to be good to very good ${ }^{(13,14)}$

\section{DEP}

We found a decreasing tendency from the caudal to rostral direction, similar to the finding in the study by Herrero et al. ${ }^{(13)}$. However, statistical significance was only noted for C7 on the left side, DEP with the lowest value. There is no generally accepted entry point for cervical pedicle screw insertion in the literature. As considering the mean DEP ranged between 22.92$23.75 \mathrm{~mm}$ and the smallest DEP was noted as $19.94 \mathrm{~mm}$ in the present study, pedicle screws at least $20 \mathrm{~mm}$ lateral to spinous process-lamina junction could be safely placed in the Anatolian population.

\section{PW}

The smallest PW in our study was $4.11 \mathrm{~mm}$, which is greater than the width reported in previous studies, except the study by Herrero et al.(13). Additionally, the PW had an increasing tendency in the distal direction, although the change was not significant at each level. Jones et al.(5) found no difference in the pull-out strengths of $2.7-\mathrm{mm}$ and $3.5-\mathrm{mm}$ pedicle screws. Thus, a width of $4.11 \mathrm{~mm}$ is sufficient to safely insert a $2.7-\mathrm{mm}$ pedicle screw. However, $2.7 \mathrm{~mm}$ pedicle screws are not widely available. Considering the majority of commercially available pedicle screws have the smallest width of $3.5 \mathrm{~mm}$, they seem 
to be safe at all levels. Moreover, considering the smallest PW being $4.11 \mathrm{~mm}$ in 2000 measurements, $4 \mathrm{~mm}$ pedicle screws can be safely used as rescue screws.

PAL

We found a significant increase in the PAL from C3 to C7, which is not consistent with the results in other morphometric studies. Additionally, this finding is in contrast to the finding in the study by Herrero et al. ${ }^{(13)}$. As the cohort sizes of our study and the study by Herrero et al. ${ }^{(13)}$ were similar, the differences in PAL might be associated with population differences or inter-rater reliability, which has been reported to be moderate to good by Herrero et al.(13) and Westermann et al.(14), and good by Rao et al.(15). In accordance with the current study's PAL values, it can be said that inserting longer screws with increasing dimensions of 2 $\mathrm{mm}$ as progressing caudally through the cervical spine starting from C3 with an $18 \mathrm{~mm}$ screw could be performed securely in the Anatolian population.

\section{PTA}

The mean overall PTA ranged from $33.52^{\circ}$ to $34.59^{\circ}$. The PTA at $\mathrm{C} 6$ was significantly higher than that at the above levels, but there was no significant difference with regard to C7. This finding is in contrast to the findings of studies that reported the smallest PTA at C7. Moreover, to our knowledge, the PTA range in our study is one of the smallest among similar studies $^{(5,7,9,10,12,14,15)}$. Similar findings were reported by Panjabi et al. ${ }^{(18)}$. As such a low trajectory angle might result in perforation of the transverse foramina, we highly recommend preoperative evaluation of cervical pedicle trajectories individually.

\section{$\mathrm{PH}$}

Although the $\mathrm{PH}$ had a decreasing tendency from the rostral to caudal direction, with the exception of $\mathrm{C7}$, it was greater than the PW at all levels, which is consistent with previous findings. Thus, the screw diameter can be safely determined according to only the PW.

\section{Study Limitations}

This study has several limitations. First, single-centre nature of the study might not necessarily represent the whole Anatolia. However, the study was performed in a government-owned academic tertiary referral care centre with ease of access by the public. The hospital is located in İzmir, which aside from being $3^{\text {rd }}$ largest city in Turkey, also has been the $3^{\text {rd }}$ city that receives domestic immigration the most for the last decade ${ }^{(19)}$. The location of the centre is close to where most of those immigrants settled, and the patient population mostly consists of those people. As the power analysis was resulted in over $90 \%$ for all evaluated parameters, the study population is considered as sufficient. Second, we included only a limited range of individuals and excluded the patients with the occurrence of any pathology related to any kind of spinal disease and prior cervical spine surgery. So, some modifications might be needed in terms of such circumstances. Third, a statistically significant difference was found between the mean ages of the genders; no correction was performed as age is not considered to be related to the measured parameters. Fourth, this was a radiomorphometric study, and clinical assessment was absent. And finally, all measurements were performed by two blinded observers in one occasion; no reliability analysis was performed. However, we believe that this study supplies useful information about radiomorphometric parameters for the Turkish spine surgeons in the accurate placement of cervical pedicle screw.

\section{CONCLUSIONS}

We performed a detailed CT-based morphometric analysis of the subaxial cervical spine in the Anatolian population. Based on these findings, pedicle screws with $3.5 \mathrm{~mm}$ width seems to be safe at all levels. A distance from $2 \mathrm{~mm}$ lateral to spinous process-lamina junction appears to be a valid screw entry point. Furthermore, it is not necessary to measure $\mathrm{PH}$, and finally, the findings regarding the pedicle insertion angle should be taken cautiously until they are supported by further studies. As a consequence, although surgical planning should be carried out on a case-by-case basis, the findings of the present study might help Turkish spine surgeons in decision-making for the accurate placement of cervical pedicle screws.

\section{Ethics}

Ethics Committee Approval: The study protocol was approved by the local institutional review board. (Date: 20.06.2017, decision no: 521).

Informed Consent: The informed consent for academic research had been taken.

Peer-review: Internally peer-reviewed.

\section{Authorship Contributions}

Concept: M.S., C.T., Design: M.S., İ.D.C., C.T., Data Collection or Processing: İ.D.C., Analysis or Interpretation: M.S., İ.D.C., C.T., S.B., S.A., Literature Search: S.B., S.A., Writing: S.B., S.A.

Conflict of Interest: No conflict of interest was declared by the authors.

Financial Disclosure: The authors declared that this study received no financial support.

\section{REFERENCES}

1. Kwon BK, Vaccaro AR, Grauer JN, Beiner JM. The use of rigid internal fixation in the surgical management of cervical spondylosis. Neurosurgery. 2007;60:118-29.

2. Coe JD, Vaccaro AR, Dailey AT, Skolasky RL Jr, Sasso RC, Ludwig SC, et al. Lateral mass screw fixation in the cervical spine: A systematic literature review. J Bone Joint Surg Am. 2013;95:2136-43.

3. Abumi K, Itoh H, Taneichi H, Kaneda K. Transpedicular screw fixation for traumatic lesions of the middle and lower cervical spine: description of the techniques and preliminary report. I Spinal Disord. 1994;7:19-28

4. Jeanneret B, Gebhard JS, Magerl F. Transpedicular screw fixation of articular mass fracture-separation: results of an anatomical study and operative technique. J Spinal Disord. 1994;7:222-9.

5. Jones EL, Heller JG, Silcox DH, Hutton WC. Cervical pedicle screws versus lateral mass screws. Anatomic feasibility and biomechanical comparison. Spine (Phila Pa 1976). 1997;22:977-82. 
6. Liu Y, Zhang B, Dai M, Xiong HC, Gao S, Li BH, et al. Anatomic study of individualized and improved pedicle screw implantation in the lower cervical spine. Int Surg. 2015;100:328-33.

7. Uğur HC, Attar A, Uz A, Tekdemir I, Egemen N, Cağlar S, et al. Surgical anatomic evaluation of the cervical pedicle and adjacent neural structures. Neurosurgery. 2000;47:1162-9.

8. Kayalioglu G, Erturk M, Varol T, Cezayirli E. Morphometry of the cervical vertebral pedicles as a guide for transpedicular screw fixation. Neurol Med Chir (Tokyo). 2007;47:102-8.

9. Abuzayed B, Tutunculer B, Kucukyuruk B, Tuzgen S. Anatomic basis of anterior and posterior instrumentation of the spine: morphometric study. Surg Radiol Anat. 2010;32:75-85.

10. Gupta R, Kapoor K, Sharma A, Kochhar S, Garg R. Morphometry of typical cervical vertebrae on dry bones and CT scan and its implications in transpedicular screw placement surgery. Surg Radiol Anat. 2013;35:181-9.

11. Simşek S, Uz A, Er U, Apaydın N. Quantitative evaluation of the anatomical parameters for subaxial cervical spondylectomy: an anatomical study. J Neurosurg Spine. 2013;18:568-74.

12. Saluja S, Patil S, Vasudeva N. Morphometric analysis of sub-axial cervical vertebrae and its surgical implications. J Clin Diagn Res. 2015;9:1-4.

13. Herrero CF, Luis do Nascimento A, Maranho DAC, Ferreira-Filho $\mathrm{NM}$, Nogueira CP, Nogueira-Barbosa $\mathrm{MH}$, et al. Cervical pedicle morphometry in a Latin American population: a Brazilian study. Medicine (Baltimore). 2016;95:e3947.

14. Westermann L, Spemes C, Eysel P, Simons M, Scheyerer MJ, Siewe J, et al. Computer tomography-based morphometric analysis of the cervical spine pedicles C3-C7. Acta Neurochir (Wien). 2018;160:863-71.

15. Rao RD, Marawar SV, Stemper BD, Yoganandan N, Shender BS. Computerized tomographic morphometric analysis of subaxial cervical spine pedicles in young asymptomatic volunteers. J Bone Joint Surg Am. 2008;90:1914-21.

16. Ludwig SC, Kramer DL, Balderston RA, Vaccaro AR, Foley KF, Albert T]. Placement of pedicle screws in the human cadaveric cervical spine: comparative accuracy of three techniques. Spine (Phila Pa 1976). 2000;25:1655-67.

17. Lee DH, Lee SW, Kang SJ, Hwang CJ, Kim NH, Bae JY, et al. Optimal entry points and trajectories for cervical pedicle screw placement into subaxial cervical vertebrae. Eur Spine J. 2011;20:905-11.

18. Panjabi MM, Duranceau J, Goel V, Oxland T, Takata K. Cervical human vertebrae: quantitative three-dimensional anatomy of the middle and lower regions. Spine (Phila Pa 1976). 1991;16:861-9.

19. Göç İstatistikleri. Türkiye İstatistik Kurumu [Internet]. http://www. tuik.gov.tr/PreTablo.do?alt_id=1067. Accessed Jul 09, 2019. 